\title{
Key for Entering Industry 4.0 in the AEC Sector
}

\section{BIM Organisation Development}

\author{
Adam Tamas Kovacs ${ }^{1}$, Mihaly Szoboszlai ${ }^{2}$, Istvan Csusz ${ }^{3}$ \\ 1,2 Budapest University of Technology and Economics, Department of Geometry \\ and Informatics ${ }^{3}$ Brick+Data \\ ${ }^{1,2}\left\{\right.$ kovacsadam|szoboszlai\}@arch.bme.hu ${ }^{3}$ istvan.csusz@brickdata.hu
}

\begin{abstract}
More and more sectors are entering Industry 4.0 but when we look around in the Architecture, Engineering and Construction industry, we do not see it happening. We wanted to investigate the reason behind this. Therefore, we conducted research among Hungarian design studios to find out what level of development they are at, and what the obstacles could be for implementing the latest technologies. This paper identifies the main problem we uncovered and discusses a possible solution. We explain what BIM Organisation Development is and why it is fundamental for architect studios who would like to enter Industry 4.0. We introduce the so-called Brick+Data Method, specifying its three essential development steps to get BIM technologies implemented and to make architect studios more efficient. Finally, we share our findings according to the feedback of the companies we worked with using this method.
\end{abstract}

Keywords: BIM, organisation development, technology implementation, Industry 4.0, design process

\section{INTRODUCTION}

The title of the eCAADe conference this year is "Architecture in the 4th Industrial Revolution". Nowadays, we can barely find an industry that has not already organised a conference about the technological achievements of Industry 4.0 and how it will transform their sector. On the other hand, we can name several promising technologies that have not lived up to expectations. We asked the question: "What is the reason behind this?" When discussing the industrial revolution, should the conversation always be about technology? Moreover, is it even clear to us what these industrial revolutions represent?

\section{WHAT DOES INDUSTRY 4.0 MEAN?}

Today, people identify Industry 4.0 with the following main technologies: communication among machines, communication among machines and "things", big data, artificial intelligence ( $\mathrm{Al})$, cloud computing, decision-supporting systems and personalised mass production. (Sztrapkovics et al. 2019)

At most of the conferences, the discussions are about the opportunities these technologies hold and how the various industries can use them. For example, big data and cloud computing would allow us to analyse a great amount of data, then to optimise workflows according to that. We have the opportunity to make data accessible to stakeholders in a 
transparent way, and afterwards, we can visualise it in order to support their decisions. With artificial intelligence, we can decentralise decision-making, thus taking some of the burden off main decision-makers. For us, the question is not what we could use a technology for, rather if people are willing to use it. Are they able to use it? Do they prefer it to previous versions? Are they able to use it in teams? Have they developed an understanding of how to use it?

There is no question that, without technology, there would be no shift between eras. However, just because there is an opportunity for something, it does not mean it will be realised. Since the envisioning method in the discipline of future research (Nováky et al. 2017), we know that applying new technology depends on more factors than just inventing the technology itself. It is a necessary term, but not adequate. Let us see how the previous shifting of eras ran their course and what kind of conclusions we can draw from this, in order to get to determine how we can benefit from the opportunities of Industry 4.0 as soon as possible.

\section{INDUSTRY 3.0 AND THE AEC SECTOR}

For the most part, we date the first industrial revolution from the appearance of steam engines, and the second from the appearance of electricity, assembly lines, and mass production. With regard to Industry 3.0, we consider that it begins either with the invention of the transistor in 1947 or from 1969 - the birth of ARPANET (the ancestor of the internet) and the Intel 4004 chip.

The main inventions of the era were the computer, automated assembly lines, internet and personal computers. From the AEC industry point of view, automated prefabrication, computer-aided design, simulations of virtual buildings, and remote design collaboration appeared.

This technology allowed the spread of telecommunication, outsourcing, digitisation of analogue equipment, and thus globalisation. The main promise of this new era was that fewer employees were needed, while productivity would grow. If we look at the productivity of the US (Figure 1), we can see that it has truly multiplied. Still, it is interesting to take a look at the efficiency of the AEC industry compared to the rest. While the economy as a whole was characterised by steep growth, the AEC sector tends to show a slight decline. This trend has not changed in the last decades. (Figure 2)
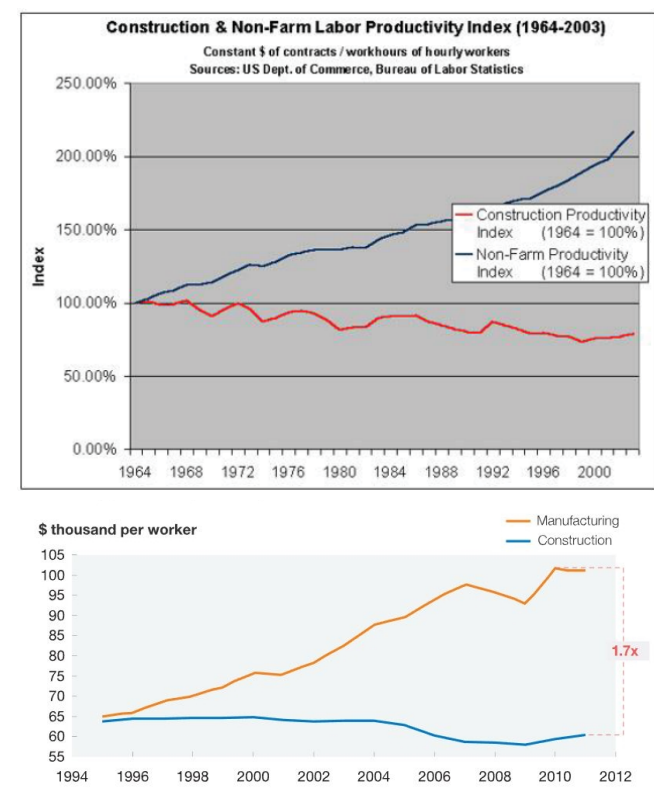

Source: Expert interviews; IHS Global Insight (Belgium, France, Germany, Italy, Spain
United Kingrom, United States): World Input-Output Database

This raises the question: Why has the efficiency of the AEC industry not grown? Could none of the technology provided by Industry 3.0 help the AEC sector? Alternatively, is it possible that the technology was available, but we simply did not implement it in the right way? Throughout our research, we looked for these answers, focusing on the design phase and design studios of the AEC industry.
Figure 1

Labour productivity

index for US

construction

industry and all

non-farm industries

Figure 2

Overview of

productivity improvement over time in the manufacturing and construction industry (McKinsey\&Company) 
Figure 3

BIM use in the Hungarian AEC industry concerning function

\section{RESEARCH CONCERNING THE TECHNO- LOGICAL DEVELOPMENT OF THE HUN- GARIAN AEC STAKEHOLDERS}

During our research, we were interested in what kind of technology and workflows design studios have already implemented and what kinds they are planning to. What barriers they have to overcome during technology implementation. To this end, we collected information from three places. From these sources, we were able to map actual Hungarian circumstances.

First, the results of an already existing online form carried out by the Lechner Knowledge Center in late 2017 with 89 participants from the AEC industry. They asked respondents what do they use BIM for. It turns out that $56 \%$ use it for documentation,
$45 \%$ for supporting the design process, $40 \%$ for quality checks. (Figure 3) These are the very basic functions of Industry 3.0, and barely half of the studios use these. Other functions are used even less.

One of the base elements of BIM usage is working with an appropriate 3-D featured CAAD application throughout the design process; no matter which brand of CAAD package is implemented and standardised by in-house rules and regulations. Hence an indicator of how organised they are working with BIM technology is if they are using CAAD templates. Only $42 \%$ said that they are using templates. The third fact that we would like to point out from this research is that lack of BIM education and training is a major setback factor for new technology adoption. (Figure 4) If we compare these results with the results

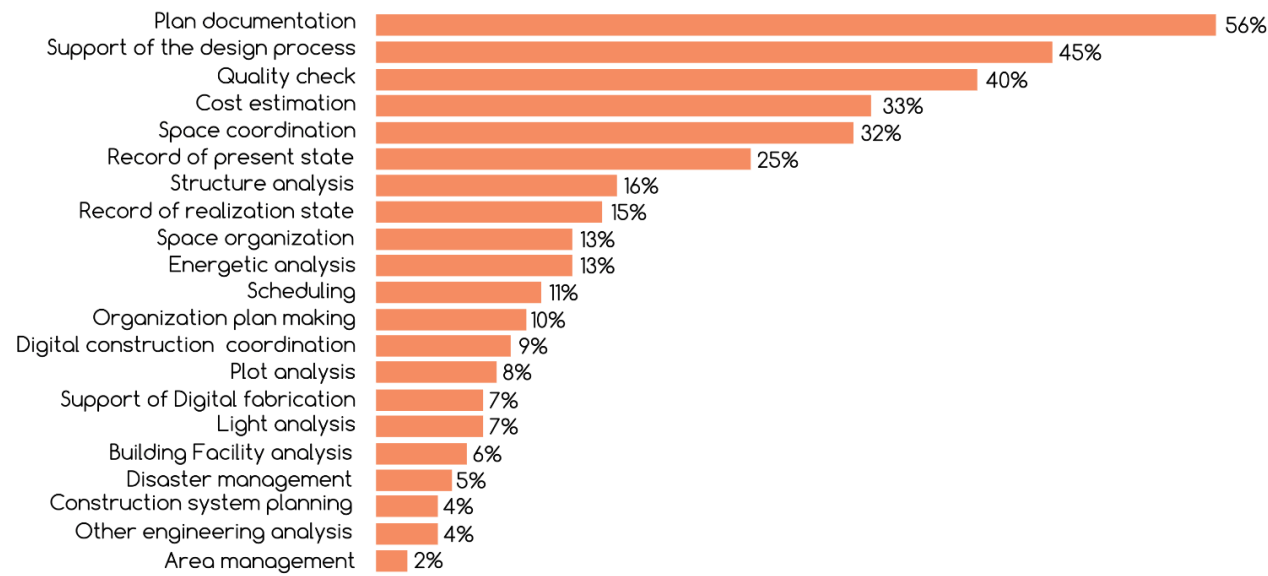

Figure 4

Top barriers of new technology adoption in the Hungarian AEC industry

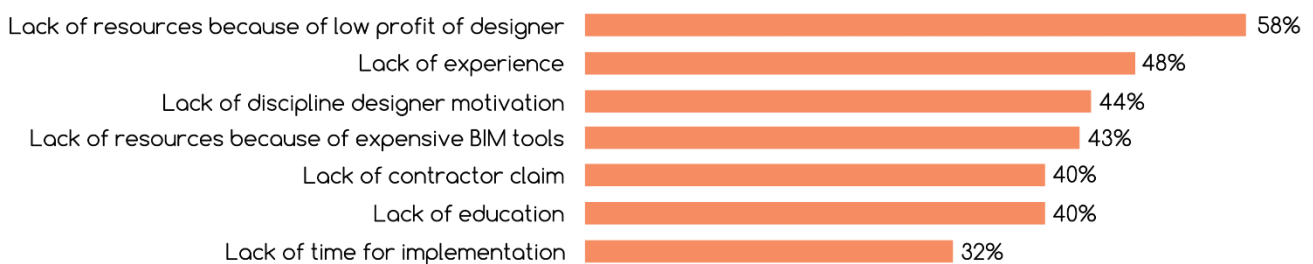


from Poland, we see that there are a lot of similarities, which suggests our findings could be more widely valid. (Kepczynska-Walczak 2018)

Secondly, a BIM survey (Porkoláb et al. 2017) prepared by three of our students and filled out by more than 100 designers and discipline designers.

Although there are more valuable data collected in the research, we are highlighting only one part of it. In Figure 5, one can follow the answers of the respondents if they are using BIM technology, not using it, or planning on using it. $42 \%$ said that they are using it already, and $50 \%$ are planning to use it, whereas $20 \%$ are not even planning to use it.

The third area of research consisted of in-depth interviews with ten design studios from Budapest, Hungary. We have highlighted three thoughts they shared with us during these interviews.

- "To sum it up, during BIM technology adoption it is not the difficulty of using BIM tools that makes the process difficult, but creating new mindsets in our colleagues".
- "Human communication plays a significant role and should be emphasised more, no matter if a BIM model exists, or no matter the design method".

- "Regarding project management, for our employees, the most difficult part is to shift from their notebook to a digital tool."

In addition, we wondered what kind of expectations Hungarian design studios have to meet in the era of Industry 4.0. Therefore, we conducted research on the future of Hungarian architectural design. (Kovacs 2018) We reviewed the forces that may transform the future of design in the next 20 years. There were two online surveys. One was filled out by 120 architects, whereas the other was completed by 160 people who were not familiar with architectural design processes but represented the "person in the street" who will affect it in other ways.

We asked the following almost taboo question: "Can you imagine a computer that can design your house or flat without an architect's intervention?"

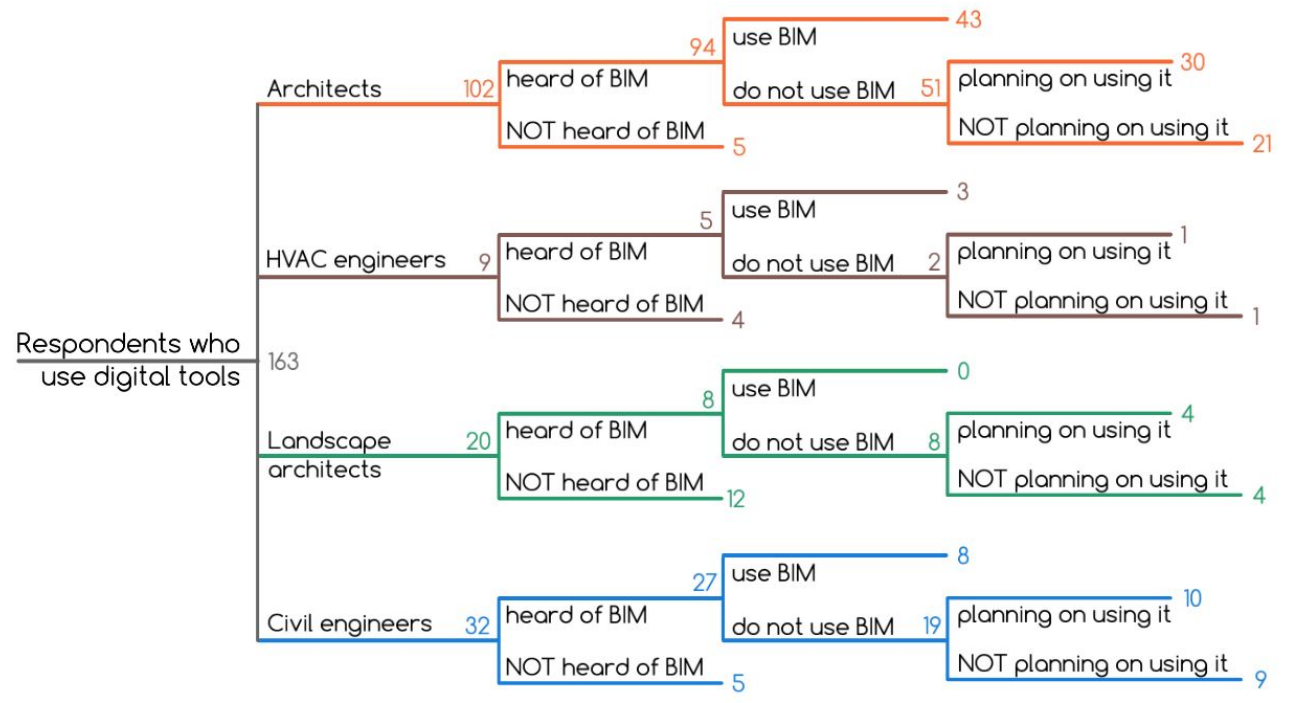

Figure 5

BIM attitude in the Hungarian AEC industry 2017 
Figure 6

Answers for the question, whether respondents can imagine a computer designing a house or flat without an architect's intervention?
In response, $58 \%$ of the architects and $72 \%$ of the non-architects could imagine a computer alone being able to design a building in 20 years. (Figure 6 )
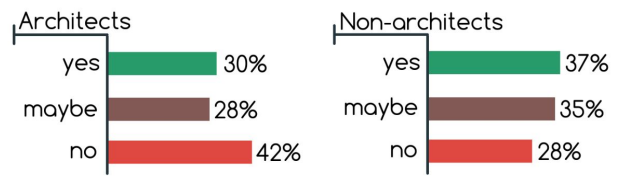

According to $35 \%$ of architects, the role of informatics and software skills will greatly increase. In the meantime, many commented that it is likely that programming skills will be necessary for architects. As for creativity, $18 \%$ said creativity is going to be more important in the next 20 years. $15 \%$ felt that soft skills such as communication, cooperation and emotional intelligence would be more important as well.

Summing up all of the results of the above researches, it appears that a great many studios see the future of design in Industry 4.0, but they barely possess the competencies to apply it. Furthermore, a significant number have not yet finished implementing Industry 3.0, even though that is a prerequisite of 4.0. They are struggling with adoption, and the barrier is not the lack of accessibility of technology, nor the quality of technology, but lack of education and workflows. If the digital company culture cannot keep up with the ecosystem of 3.0, then it is not possible to step up to the next level, because it is based on a maintained informatics infrastructure, databases filled with correct data, a culture of online collaboration, and mature human-computer interaction.

During our interviews, some architects considered buying new software and including half-day training as an implementation process. However, if we look at the implementation of technology from a socio-technical view (Arayici et al. 2010), it turns out it has three foundations. The first is the installation of the technology, which means installation of software and/or hardware. The second is the creation of workflows. The third is the development of the employees' skills and motivation. In order to have a suc- cessful implementation process, all three of these aspects are crucial. If there is no technology, there is nothing to use. If there is no correct workflow for employees to follow, then many errors and difficulties will interfere with the use of that technology. If the employees are not ready for the given technology, they are going to resist. This means, practically speaking, that it is not enough to buy BIM software. Use of the software must be taught, the employees must be prepared and motivated, and the used cases precisely applied.

There are several challenges that design studios have to face while undergoing development. These can be put into five categories: customer related, company related, social aspect related, technology related, supporting element related. (Tulenheimo 2015) BIM organisation development provides an approach to handle these matters together successfully.

\section{BIM ORGANIZATION DEVELOPMENT}

Nowadays, professionals and scientific society both call introducing new technology to design studios BIM (Building Information Modelling) implementation. We think using this term is not accurate and may be misleading about the significance of the process. According to the Cambridge Dictionary, implementation means: "act of putting a plan to action" or "start to use something". On the one hand, every company must develop its plan and strategy concerning the introduction of new technologies before they can put it into practice. So, in this sense, this process is more than just an implementation process. On the other hand, it may be misleading because it does not suggest how fundamental an effect it has on a company. This process contains several implementations of different technologies, and it is so complex that the whole organisation has to adapt to it.

Therefore, we prefer to call this process BIM Organisation Development because it better expresses the essence of the process. Organisational Development (OD) became a scientific discipline with literature dating back to the 1930s. "Organisation devel- 
opment is a systemwide application and transfer of behavioural science knowledge to the planned development, improvement, and reinforcement of the strategies, structures, and processes that lead to organisation effectiveness." (Cummings et al. 2014) We are merging the knowledge of OD with the knowledge of BIM and the latest digital technologies. We define BIM Organization Development as following: "It is a planned and systematic approach to improve the effectiveness of a design studio focusing on development of technology, workflows and employees simultaneously."

The market lacks services that give comprehensive business and process developments for design studios. Nowadays, design studios focusing solely on technological tools (Hochscheid et al. 2018) with maybe some hard-skill training is a good scenario. However, organisation development is as effective as the least developed part of it, so it is important to highlight the human factor of this development, which is not usually taken as seriously as it should be. It is possible to have great technology and efficient processes, but if and when it is put to use by employees, we may find that it does not work because of a lack of knowledge, lack of skills, or lack of motivation. Adopting new habits - and BIM OD is about creating and applying new habits - is one of the most difficult things in everyday life. Every employee has their own background and is going to experience this development as difficult or as easy accordingly. Hence, it is beneficial if we take their attitudes and personality into account in order to decide on the level of new technology adoption and how quickly we would like to finish the process. (Tulenheimo 2015)

We named our BIM Organisation Development process "Brick+Data Method". So far, we have used this method on three organisations: an 8-person studio, a 12-person studio, and the core team of the Hungarian Solar Decathlon Team, which consists of 30 people.

There are several approaches to BIM implementation. (Lindbald et al. 2019; Hochscheid et al. 2018) In our method, the audit is more comprehensive compared to other BIM implementation processes. We take into account factors, from hardware configuration to the personalities of the employees. Next, we believe that the facilitator of the BIM OD is crucial. They need to reach all of the employees and

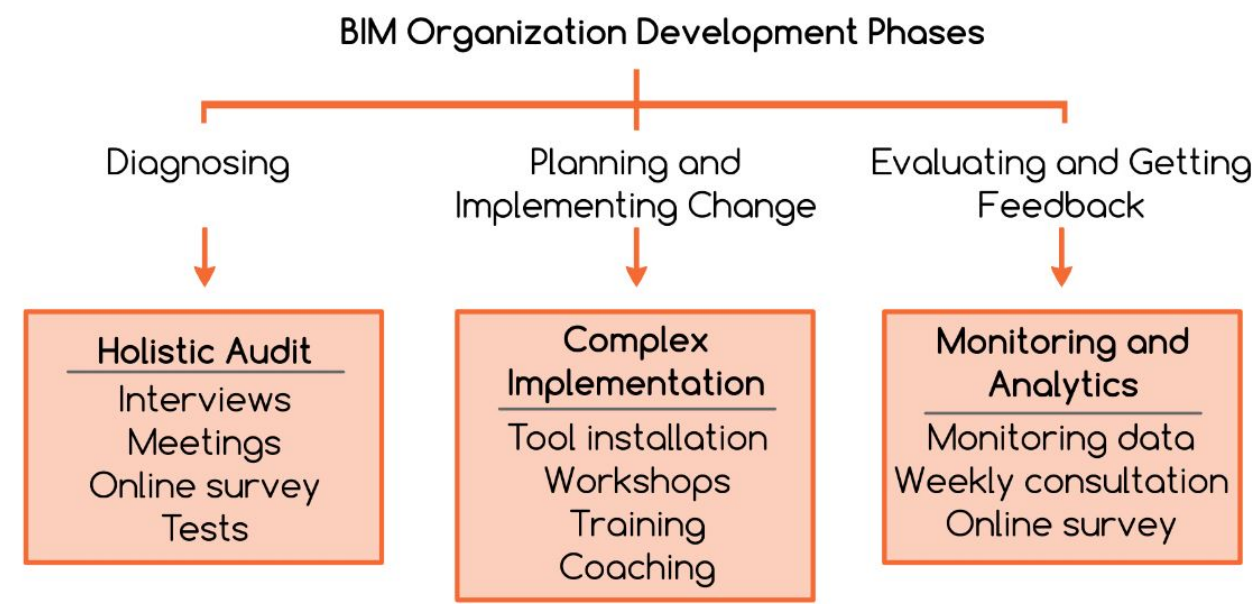

Figure 7

BIM Organisation

Development

Phases with

Brick+Data method 
earn their trust in order for them to learn new skills and change their habits. The facilitator has to be someone who has both strong hard and soft-skills and needs to have a respected experience in such development. Hence, we do not think a student intern would be an ideal choice for this! Our method includes the following three phases, based on the traditional OD steps. (Figure 7)

\section{HOLISTIC AUDIT}

To carry out developments on a design studio, we must first survey the level they are at the moment. Then, conduct a GAP analysis (Blokdyk 2017), which is a comparison of actual performance with potential or desired performance of the company. We do this in a holistic manner, which means we spread out the scope as much as our present knowledge allows us. We organise the audit under the same three topics: technology, workflows, and employees.

For the technology aspect, we benchmark the hardware park and a list of the software infrastructure. We analyse the file system and the nomenclature, and look at the templates used by different software, if they exist. Finally, we take office ergonomics into account. For example, in one case, it turned out that the bottleneck was not the BIM software or unsatisfying communication, but the uncomfortable chairs and small screens.

In the workflow section, we break down the design steps: proposition, project start, design, project closing, etc. We do not only take into account the procedures concerning the architectural processes, but all the business processes as well - for example, the inner team communication, whether it is a weekly meeting, emails, use of the calendar, or the use of project management software. It even includes communication with the discipline designers, partners, and marketing. At the HR level, we create an HR book where the surveys filled out by all the employees can be found: with the various aspects psychological profile, motivational factor, and soft and hard skills.

During the audit, we use different methods to collect data. We carry out personal interviews and hold focus-group interviews with different team setups. We fill out an online survey with the team and administer different types of tests: ARCHICAD or Revit, Excel, and DISC personality test.

\section{COMPLEX IMPLEMENTATION}

In this phase, we implement our development suggestions accepted by the leadership of the office. This has two important steps.

The first is that we work out the given topic closely with the employees during facilitated workshops. The person who is facilitating these is somewhat similar to a BIM-Agile Coach (Gless et al. 2018) except he is mixing other techniques beside agile ones. As a result of these workshops, descriptions, lists, and templates are created, which organise the studio. At the same time, employees internalise these while working on them, which will have a good effect when they start working in a new way.

The other is that we make a digital booklet for the operation of the studio. This is a collective knowledge base where we document the workflows worked out together with the company. This is fundamentally a collectively editable document, and anyone can add suggestions or comments over time.

\section{MONITORING AND ANALYTICS}

In the last phase, we explore how implementation operates in practice from the point of view of technology, workflow, and the employee. This phase is important because new routines need time to fully internalise in order to become a habit. It may also happen that an upgrade does not work as expected. In this case, we need to investigate it and modify it. We collect information regularly, both quantitatively and qualitatively, to carefully track the process.

\section{CONCLUSION}

In our paper, we conducted research where we identified that - at least in the Hungarian AEC sector - companies have not yet entered Industry 4.0, because they have still to adopt 3.0 fully. Our theory, based on our experiment, is that the reason for this lag is that 
companies focus only on technology, skipping processes and human aspects. Consequently, we propose that the key to entering Industry 4.0 is BIM Organisation Development.

We showed how we put this into practice with Brick+Data Method, developing all three aspects of the company. According to the studios we worked with, there were two additional benefits of the development what we could not see in advance.

The first was that during the focus-group interviews where we were supposed to get information about the company, the employees also heard a lot of new information. Their knowledge about the company, the processes and the motives and competences of each other synchronised.

The second benefit was that the big picture of the studio revealed itself to the leadership. During everyday work, leadership tends to get lost in the actual projects and tends to forget about the big picture and long-term goals. When they visually see the whole company from all the important aspects, it gives them a firmer basis for their decision-making.

Based on the monitoring phase of the development, studios we worked with became more organised and more efficient, closing the implementation process of Industry 3.0 and being ready to enter Industry 4.0 .

\section{FUTURE WORK}

We continuously upgrade our method based on the latest BIM OD projects we take part in. One of our next steps is to carry out a detailed analysis on the comparison of our method to the BIMe Initiative [1]. Especially, the topic of measuring BIM performance (Succar et al. 2012) which gained our attention, because in our experience, making KPIs (Key Point Indicator) in certain parts of the development is a great challenge.

\section{REFERENCES}

Ahuja, R, Sawhney, A and Arif, M 2017, 'Prioritizing BIM Capabilities of an Organization: An Interpretive Structural Modeling Analysis', Procedia Engineering,
196, pp. 2-10

Ahujaa, R, Sawhneyb, A and Arifc, M 2017, 'Prioritizing BIM Capabilities of an Organization: An Interpretive Structural Modeling Analysis', Procedia Engineering, 196, pp. 2-10

Arayici, Y, Coates, P, Kosela, L, Kagioglou, M, Usher, C and O'Reilly, K 2010, 'Technology Adoption in the BIM Implementation for Lean Architectural Practice', $A u$ tomation in Construction, 20, pp. 189-195

Blokdyk, G 2017, Gap Analysis: The Definitive Handbook, CreateSpace Independent Publishing Platform

Cummings, TG and Worley, CG 2009, Organization Development and Change, South-Western Cengage Learning

Gless, HJ, Halin, G and Hanser, D 2018 'Need of a BIMagile Coach to Oversee Architectural Design', Computing for a better tomorrow - Proceedings of the 36th eCAADe Conference, pp. 445-450

Hochscheid, E and Halin, G 2018 'BIM Implementation in Architecture Firms', Computing for a better tomorrow - Proceedings of the 36th eCAADe Conference

Kepczynska-Walczak, A 2018 'Building Information Modelling for 2020+ Realm', Computing for a better tomorrow-Proceedings of the 36th eCAADe Conference, pp. $271-280$

Kovacs, AT 2018 'The Future of Architectural Design in the next 20 year in Hungary', A múltból átívelő jövő : VIII. Magyar (Jubileumi) Jövőkutatási Konferencia : 50 éves a magyar jövőkutatás, Budapest, pp. 329-339

Lindblad, H and Vass, S 2015, 'BIM implementation and organisational change: A case study of a large Swedish public client', Procedia Economics and Finance, 21, pp. 178-184

Nováky, E, Hideg, E and Tóthné Szita, K 2017, 'Futures Studies Serving the Development of Future Orientation in Hungary', World Futures Review, 9, pp. 1-12

Succar, B, Sher, W and Williams, A 2012, 'Measuring BIM performance: Five metrics', Architectural Engineering and Design Management, 8, pp. 120-142

Sztrapkovics, B and Pataki, B 2019'The Opportunities of Simultaneous Application of Lean and Industry 4.0 in Logistics of the Construction Industry', Logistics Almanach

Tulenheimo, R 2015, 'Challenges of implementing new technologies in the world of BIM - Case study from construction engineering industry in Finland', Procedia Economics and Finance, 21, pp. 469-477

[1] https://bimexcellence.org/

[2] http://lechnerkozpont.hu/cikk/a-bim-kerdoiv-ered menyei 